\title{
Reactive Extraction of Citric Acid Using Different Extractants: Equilibrium, Kinetics and Modeling
}

\author{
N. Thakre, ${ }^{a}$ D. Datta, ${ }^{\mathrm{b}}$ A. K. Prajapati, ${ }^{\mathrm{c}}$ P. K. Chaudhari, ${ }^{\mathrm{d}}$ and D. Pal ${ }^{\mathrm{d},{ }^{,}}$ \\ aDepartment of Chemical Engineering, IIT Kharagpur - 721302, India \\ ${ }^{b}$ Department of Chemical Engineering, MNIT Jaipur - 302017, India \\ 'Department of Chemical Engineering, IESI, Indore - 452012, India \\ ${ }^{d}$ Department of Chemical Engineering, NIT Raipur, Raipur - 492010, India
}

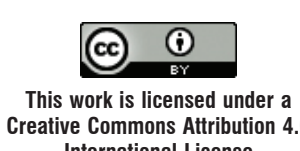

Creative Commons Attribution 4.0 International License

doi: $10.15255 / \mathrm{CABEQ} .2016 .859$

Original scientific paper

Received: March 7, 2016

Accepted: November 26, 2017

Recovery of citric acid from biotechnologically produced low concentration aqueous solution has attracted several separation techniques for the downstream processing. Amongst them, reactive extraction is a convenient, cheap, and effective method. Three different extractants are used in this study, namely tri- $n$-butyl phosphate (TBP), tri- $n$-octylamine (TOA), and Aliquat 336 (A336), all diluted in methyl-iso-butyl ketone (MIBK). The isothermal batch experiments were performed for the equilibrium and kinetic studies at $T=300.15 \pm 1 \mathrm{~K}$. Around $92 \%$ extraction efficiency $(E \%)$ was obtained using $20 \%$ $(\mathrm{v} / \mathrm{v})$ TOA in MIBK. Based on the overloading of amine $(Z>0.5),(2: 1)$ acid:extractant complex in TOA+MIBK phase was proposed. Kinetics of extraction of citric acid $\left(0.2-0.8 \mathrm{kmol} \mathrm{m}^{-3}\right)$ was also performed in a Lewis-type stirred cell, using TOA in MIBK. The extraction reaction was occurring in the diffusion film. The second order rate constant was calculated as $k_{2}=0.0351 \mathrm{~m}^{3} \mathrm{kmol}^{-1} \mathrm{~s}^{-1}$. The extraction parameters were estimated by differential evolution optimization technique. Optimal value of equilibrium constant, $K_{\mathrm{E}}$, was found to be $3.6 \cdot 10^{-3}\left(\mathrm{~m}^{3} \mathrm{kmol}^{-1}\right)^{2}$, for the reactive extraction of citric acid using $20 \%$ TOA in MIBK, and was found in close agreement with experimental values.

Keywords:

reactive extraction, citric acid, differential evolution, modeling, equilibrium, kinetics

\section{Introduction}

In a recent study, the demand for citric acid is reported to be increasing at a rapid rate of $5 \%$ per year with predictions of its value in the global market at USD 3.6 billion toward 2020 in both liquid and anhydrous form. ${ }^{1}$ This compound bearing the chemical formula $\mathrm{C}_{6} \mathrm{H}_{8} \mathrm{O}_{7}$ (2-hydroxypropane-1,2,3tricarboxylic acid), has phenomenal physicochemical properties: high solubility in water, palatability, chelating power and nontoxicity, etc. It is most common among carboxylic acids and naturally occurs in citrus fruits. The applications in food and beverages industries as acidulate, as well as in other pharmaceutical and chemical products have put the acid in the category of valuable products. It is used as an additive to many drinks to enhance flavor, to increase stability in soft drinks and syrups, and it is also used to prevent color change by oxidation. ${ }^{2}$ It is used in citrus juices to improve taste and increase shelf life. ${ }^{3}$ The production of citric acid through bioroute is emerging as a promising alternative for the synthetic route due to ever-increasing prices of petroleum feedstocks. ${ }^{4}$ The downstream processing, i.e. separation of acid from aqueous solution is a

${ }^{*}$ Corresponding author: E-mail: dpsingh.che@nitrr.ac.in challenging task, and costs almost half the production cost. Therefore, an efficient alternative separation technology is required to make the overall recovery process economically feasible. At present, the commonly used recovery methods employed are electrodialysis, membrane separation, precipitation, crystallization, and so forth. However, each method has its own limitations and drawbacks. Recently, reactive extraction has emerged as more economic and convenient over other recovery techniques. ${ }^{5-7}$ It is especially suited when the product to be recovered is inhibitory and concentration is less than 10 wt \%. ${ }^{5,6}$ It matches the conditions in a fermentation broth and thus this promising technology has been widely adopted for carboxylic acid recovery.

The extraction combined with chemical reaction offers efficient separation. The reactive species used for this purpose are extractants that very specifically extract carboxylic acids leaving behind foreign compounds in the fermentation broth. The first category of extractants include carbon-bonded oxygen donor that consists aliphatic, aromatic, and substituted hydrocarbon solvents. Secondly, there are phosphorus-bonded oxygen donor extractants, such as tri- $n$-butyl phosphate (TBP), trioctyl phosphine oxide (TOPO), etc., and third category com- 
prises of high molecular weight aliphatic amine extractants, such as tri- $n$-octyl amine (TOA), Aliquat 336 (A336), etc. ${ }^{5-9}$ As these extractants are costly as well as viscous, they are often employed after dilution in some conventional solvent (diluent). The diluent provides the desired solvation media to the extractant by tuning its desired physicochemical properties. Diluents are classified into inactive and active diluents, where the former includes aliphatic and aromatic hydrocarbons, and the latter has a functional group attached to it, such as alcohols, ketones, esters, ethers, etc. Doubtlessly, active diluents provide a better solvation media to the carboxylic acid, and hence show greater efficiency. ${ }^{5}$

Although studies on reactive extraction of various carboxylic acid are abundant in literature, the same for complete extraction study (equilibrium, kinetics and modeling) for citric acid are limited, a handful of research work can be found in the literature including equilibrium ${ }^{5-12}$ and kinetic studies ${ }^{12-13}$ of citric acid extraction. Bizek et al. ${ }^{9}$ were the first to study the physical and reactive extraction equilibria of citric acid in different diluent and trialkyamine as an extractant. The tertiary amine (e.g. TOA) reacts with the undissociated form of acid to give salts. ${ }^{8}$ The affinity to citric acid solvation of active diluents having different functional group are observed in the order of chloroform $<$ aromatics $<$ MIBK< $<$ octanol. They reported the acid-amine, acid.(amine) $)_{2}$ complexes for extraction of citric acid that confirm the overloading of acid by trialkylamine. Aiming for a higher degree of extraction, Nikhade et al. ${ }^{10}$ used $30 \%$ Alamine 366 in methylisobutylketone (MIBK) and found the distribution coefficient up to 67.147. They proposed the extraction accompanied by chemical reaction with a second order rate constant $0.013 \mathrm{~m}^{3} \mathrm{kmol}^{-1} \mathrm{~s}^{-1}$. Poposka et al. ${ }^{12}$ studied the extraction equilibria and kinetics using isodecanol/n-paraffin solution of TOA. They reported the value of $Z_{\max }$ lying between $0.67-0.54$ and suggested the existence of various stoichiometry.

The experimental and modeling studies on reactive extraction equilibria of citric acid using TBP, TOA, and A336 as extractants diluted in butyl acetate, decanol, and benzene has been published in our previous article. ${ }^{14}$ Among the active diluents, MIBK has been reported in the literature as an efficient solvent for physical extraction of citric and other carboxylic acids. ${ }^{15}$ Nevertheless, it provides a good solvation medium to the extractants such as TOA, Alamine 336, etc. However, the experimental data is lacking in the literature for comparative studies on equilibrium behavior of different extractants and MIBK as a diluent. The present work aims at analyzing the extraction efficiency and liquid-liquid equilibria of citric acid using TBP, TOA, and A336 in MIBK. The stoichiometry of acid-extract- ant complex in these three systems was analyzed graphically, as well as using the modeling approach with differential evolution ${ }^{16}$ as an optimization technique. This apart, investigating TOA+MIBK system as the most efficient extraction system in the extraction equilibrium studies, the same has been chosen for the kinetic studies of reactive extraction of citric acid from dilute aqueous solutions.

\section{Experimental}

\section{Materials}

Citric acid was obtained from Merck Co. Ltd. India. The extractants, tri-n-octylamine (TOA) and A336 were supplied by Sigma Aldrich, India; and tri- $n$-butyl phosphate (TBP) was received from Loba Chemie, India. The Millipore (Merck) purified water was used for preparing the aqueous solutions. All the chemicals used were of analytical grade and used as received. The physicochemical properties of reagents used in the present study are summarized in Table 1.

Table 1 - Physicochemical properties of chemicals used

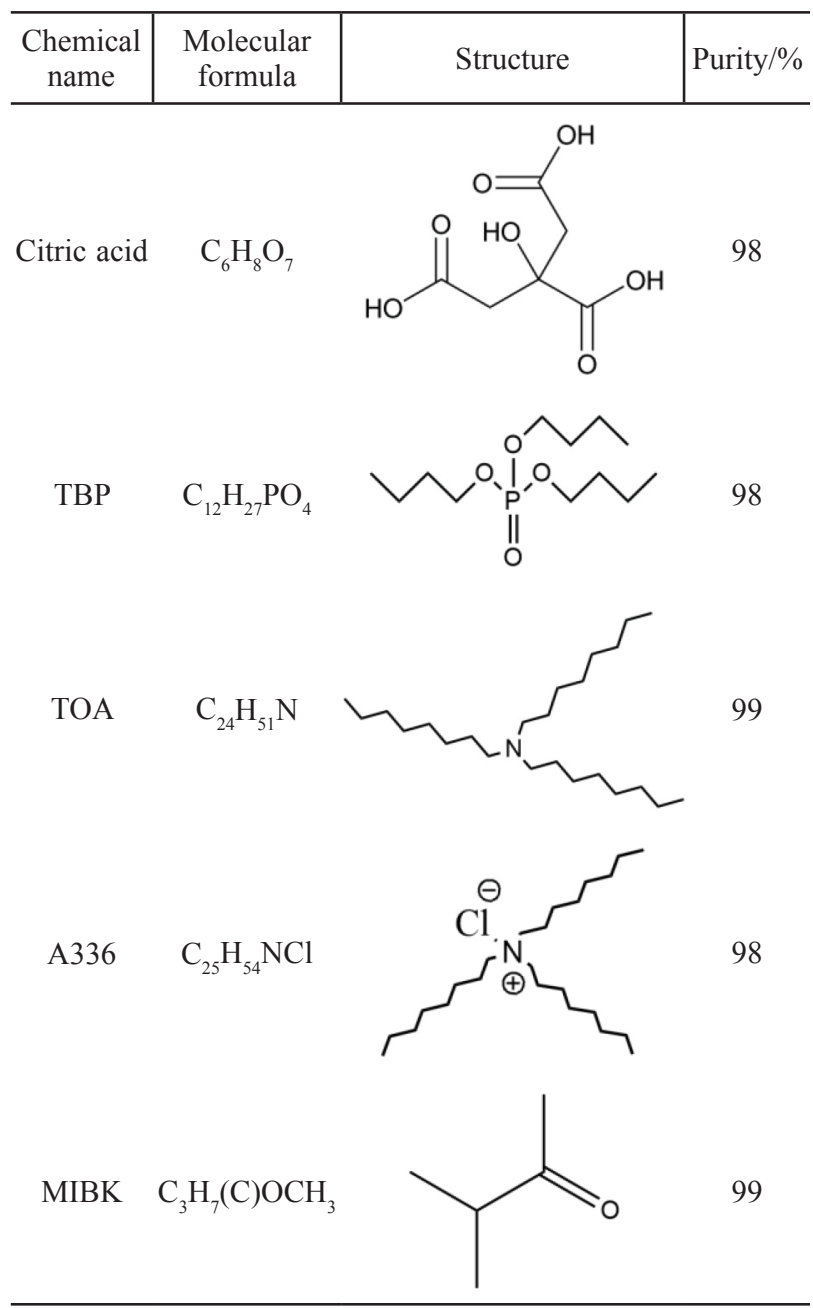




\section{Methods}

\section{Equilibrium studies}

Through the bio-route, citric acid was produced in $\sim 0.53 \mathrm{kmol} \mathrm{m}^{-3}$ concentration, and hence, the low concentration of aqueous phase $\left(0.2-0.8 \mathrm{kmol} \mathrm{m}^{-3}\right)$ was prepared and used. ${ }^{17}$ The different percentage of extractant (10-50\% (v/v)) dissolved in diluents, MIBK, were taken for the equilibrium studies. An equal amount of organic phase (extractant+MIBK) and aqueous phase (citric acid solution) were taken and mixed for 2 hours in a temperature-controlled water bath shaker (Remi Equipment Pvt. Ltd., India) at $T=300.15 \pm 1 \mathrm{~K}$. The samples were allowed to settle for clear phase separation for $4 \mathrm{~h}$. Shaking time and settling time was optimized in separate experiments. Citric acid concentration in the aqueous phase was determined by HPLC system (Young Lin Instruments, South Korea) equipped with a quaternary pump and vacuum degasser. A reverse phase column $\mathrm{C}-18$, and a UV/Vis detector at $210 \mathrm{~nm}$ were used. Mobile phase was an aqueous solution of phosphoric acid and potassium di-hydrogen phosphate, with a flow rate of $0.6 \mathrm{~mL} \mathrm{~min}^{-1} \cdot{ }^{17}$ Samples were sonicated and filtered through a Ran Disc $0.22 \mu \mathrm{m}$ PTFE membrane before injection into HPLC. To ensure the reproducibility of results, all analyses were repeated twice under identical conditions, and consistency was within $\pm 2 \%$. The mean value was used for further calculations. Acid concentration in organic phase was obtained by material balance.

\section{Kinetic studies}

Kinetics experiments for citric acid extraction were performed in a Lewis-type stirred cell that was designed similar to that used by Wasewar et al. ${ }^{18}$ and Gaidhani et al. ${ }^{19}$ The cell was configured with a flat bottom with $6.5 \mathrm{~cm}$ inner diameter, and having total interfacial area of $33.18 \mathrm{~cm}^{2}$. The stirred cell was firstly filled with $100 \mathrm{~mL}$ aqueous solution of citric acid of different concentrations. The dual stirrer with four-flat blade paddle of $4.8 \mathrm{~cm}$ in diameter and $1 \mathrm{~cm}$ in width, was adjusted to $1 \mathrm{~cm}$ below and above the interface of aqueous and organic phase. A known volume $(100 \mathrm{~mL})$ of the organic mixture of extractant (TOA) and diluent (MIBK) were then added in the vessel, and reactive extraction was carried out for a definite period. The sampling volume was kept low $(1 \mathrm{~mL})$, so that volume change is negligible.

\section{Theory}

\section{Reactive extraction equilibria}

The reactive extraction equilibrium of tricarboxylic acid using different extractants $(E)$ can be represented by Eq. 1, which shows the acid:extractant complex formation at the interphase ${ }^{7}$.

$$
m \mathrm{H}_{3} \mathrm{~A}+n \bar{E} \rightleftharpoons \overline{\left(\mathrm{H}_{3} \mathrm{~A}\right)_{m} E_{n}}
$$

where, $m$ and $n$ are the stoichiometric coefficients, and the bar over the species represents the organic phase. The extraction equilibrium constant could be defined as Eq. 2.

$K_{\mathrm{E}}=\frac{\left[\overline{\left(\mathrm{H}_{3} \mathrm{~A}\right)_{m} E_{n}}\right]}{\left[\mathrm{H}_{3} \mathrm{~A}\right]^{m}[\bar{E}]^{n}}=\frac{\left[\overline{\left(\mathrm{H}_{3} \mathrm{~A}\right)_{m} E_{n}}\right]\left(1+K_{a} /\left[\mathrm{H}^{+}\right]\right)^{m}}{\left[\mathrm{H}_{3} \mathrm{~A}\right]_{\mathrm{T}}^{m}[\bar{E}]^{n}}$

where, $\left[\mathrm{H}_{3} \mathrm{~A}\right]_{\mathrm{T}}$ is the total (ionized+unionized) acid concentration and $\mathrm{Ka}$ is the dissociation constant of citric acid. Also, distribution coefficient of the acid between aqueous and organic phase may be correlated as Eq. 3 .

$$
K_{D}=\frac{\left[\overline{\mathrm{H}_{3} \mathrm{~A}}\right]_{\mathrm{T}}}{\left[\mathrm{H}_{3} \mathrm{~A}\right]_{\mathrm{T}}}=m \frac{\left[\overline{\left(\overline{\left.\mathrm{H}_{3} \mathrm{~A}\right)_{m} E_{n}}\right.}\right]}{\left[\mathrm{H}_{3} \mathrm{~A}\right]_{\mathrm{T}}}
$$

The Eq. 2 and Eq. 3 may be combined to derive the relation between equilibrium constant and distribution coefficient as represented by Eq. 4.

$$
K_{E}=\frac{K_{D}\left(1+K_{a} /\left[\mathrm{H}^{+}\right]\right)^{m}}{m\left[\mathrm{H}_{3} \mathrm{~A}\right]_{\mathrm{T}}^{m-1}[\bar{E}]^{n}}
$$

The extractant concentration at equilibrium $[\bar{E}]$ can be obtained by using Eq. 5 .

$$
[\bar{E}]=[\bar{E}]_{\text {in }}-K_{D} n\left[\mathrm{H}_{3} \mathrm{~A}\right]_{\mathrm{T}} / m
$$

By combining Eqs. 4 and 5, a model equation is developed, which can be used to obtain optimized values of $K_{\mathrm{E}}, m$, and $n$ using numerical approach ${ }^{15}$.

$$
K_{\mathrm{D}}=m K_{\mathrm{E}}\left([\bar{E}]_{\text {in }}-K_{\mathrm{D}} n \frac{\left[\mathrm{H}_{3} \mathrm{~A}\right]_{\mathrm{T}}}{m}\right)^{n} \frac{\left[\mathrm{H}_{3} \mathrm{~A}\right]_{\mathrm{T}}^{m-1}}{\left(1+K_{a} /\left[\mathrm{H}^{+}\right]\right)^{m}}
$$

The acid-extractant complex formation can also be predicted using loading ratio $(Z)$. It is defined as the extent to which the organic phase (extractant + diluent) can be loaded with acid:

$$
Z=\frac{\left[\overline{\mathrm{H}_{3} \mathrm{~A}}\right]}{[\bar{E}]}
$$

The value of $Z$ depends upon the extractability of the acid, its aqueous concentration, and the nature of the extractant. Thus, for lower loading of amine i.e. $Z<0.5$, (1:1) acid: TOA complex formation can be assumed and $K_{\mathrm{E}}$ is related to $Z$ as: ${ }^{2}$

$$
\frac{Z}{1-Z}=K_{\mathrm{E} 1}\left[\mathrm{H}_{3} \mathrm{~A}\right]
$$


where, $K_{\mathrm{E} 1}$ is equilibrium complexation constant for $(1: 1)$ acid:TOA complex. However, in the case of higher loading values, that is $(\mathrm{Z}>0.5)$, complexes with higher stoichiometry are also formed. For $(2: 1)$ acid:TOA complex formation, the corresponding relation can be written as,

$$
\frac{Z}{2-Z}=K_{\mathrm{E} 2}\left[\mathrm{H}_{3} \mathrm{~A}\right]^{2}
$$

where, $K_{\mathrm{E} 2}$ is equilibrium complexation constant for (2:1) acid:TOA complex. Eq. 9 and Eq. 10 can be used for determining the equilibrium complexation constant and stoichiometry of acid-extractant complex graphically by fitting the experimental data.

The modified loading ratio $\left(Z_{\mathrm{m}}\right)$ is introduced to evaluate the loading by extractant only that can be obtained by subtracting contribution by diluents alone from the total loading values, $Z$, as:

$$
\mathrm{Z}_{\mathrm{m}}=Z-v \mu \text {; where, } \mu=\frac{\left[\overline{\mathrm{H}_{3} \mathrm{~A}}\right]^{\text {diluent }}}{[\overline{\mathrm{E}}]^{\circ}}
$$

Consequently, Eq. (8) and Eq. (9) could be modified to Eq. (11) and Eq. (12), respectively.

$$
\begin{aligned}
& \frac{Z_{\mathrm{m}}}{1-\mathrm{Z}_{\mathrm{m}}}=K_{\mathrm{E} 1}\left[\mathrm{H}_{3} \mathrm{~A}\right] \\
& \frac{Z_{\mathrm{m}}}{2-Z_{\mathrm{m}}}=K_{\mathrm{E} 2}\left[\mathrm{H}_{3} \mathrm{~A}\right]^{2}
\end{aligned}
$$

\section{Reactive extraction kinetics}

Doraiswamy and Sharma ${ }^{20}$ proposed the kinetic theory of extraction accompanied with chemical reaction to determine its effect on the specific rate of mass transfer. Differential mass balance of the batch system for the organic phase can be presented as Eq. 13:

$$
\frac{\mathrm{d}\left[\overline{\mathrm{H}_{3} \mathrm{~A}}\right]}{\mathrm{d} t}=k_{\mathrm{L}}\left(\frac{A_{\mathrm{c}}}{V_{\text {org }}}\right)\left({\overline{\mathrm{H}_{3} \mathrm{~A}}}^{*}-\overline{\mathrm{H}_{3} \mathrm{~A}}\right)
$$

where, $k_{\mathrm{L}}$ represents physical mass transfer coefficient whereas, $\mathrm{H}_{3} \mathrm{~A}$ and $\overline{\mathrm{H}_{3} \mathrm{~A}}$ are equilibrium and aqueous phase acid concentrations, respectively. They used the film and renewal theories with physicochemical and hydrodynamic parameters, and classified the systems into four regimes depending on their relative diffusion and reaction rates.

Regime 1: Very slow reaction occurring in the bulk liquid phase with practically no reaction in the liquid film. Regime 2: Slow reaction in which the diffusion rate is higher than the rate of the homogeneous bulk phase reaction. Regime 3: Fast reaction occurring in the diffusion film. Regime 4: Instantaneous reaction in which the reaction is so fast that the two reactants cannot co-exist and a reaction plane is formed in the diffusion film.

The discerning mechanism is suggested by Doraiswamy and Sharma ${ }^{20}$ for the extraction accompanied with a chemical reaction in a stirred cell. The expression for Regime 1, extraction accompanied by a slow general order chemical reaction is:

$$
R_{\mathrm{A}} \propto l\left[\mathrm{H}_{3} \mathrm{~A}\right]^{m}\left[E^{\mathrm{o}}\right]^{n}
$$

Thus, Eq. 14 can be written as:

$$
R_{\mathrm{A}}=l k_{\mathrm{mn}}\left[\mathrm{H}_{3} \mathrm{~A}\right]^{m}\left[E^{\mathrm{o}}\right]^{n}
$$

where, $R_{\mathrm{A}}$ is the specific rate of extraction, $l$ is the liquid volume hold-up of extractant $(E)$ phase based on the total liquid volume, and $k_{m}$ is the specific rate constant. In the present study, $R_{\mathrm{A}}$ was obtained by varying the initial concentration of citric acid in the organic phase. Only initial rates were taken into consideration to avoid problems due to reversibility of extraction reaction. The condition for the reaction to fall into Regime 1 is given as:

$$
k_{\mathrm{L}}\left[\mathrm{H}_{3} \mathrm{~A}\right] \gg l k_{m n}\left[\mathrm{H}_{3} \mathrm{~A}\right]^{m}\left[E^{\mathrm{o}}\right]^{n}
$$

\section{Parameter determination using differential evolution technique}

The stoichiometry of the acid:extractant complex should be known for design of extractor. This can be predicted using the Chemodel given by Eq. (6). ${ }^{18}$ There are two parameters to be determined, i.e. $K_{\mathrm{E}}$ and $m$ by setting $n$ equal to unity. The optimization technique adopted in this study is the differential evolution, which is based on the genetic algorithm. This method is useful as it finds the global optimum, while the gradient-based techniques may trap into the local optimum. The objective function based on least squares error between experimental and model values of $K_{\mathrm{D}}$ were minimized for predicting the acid amine (TOA) stoichiometry, $m$ and $n$ for the complexation reaction.

$$
\text { Objective function }=\sum_{\text {data points }}\left(k_{\mathrm{D}}^{\text {exp }}-k_{\mathrm{D}}^{\text {mod }}\right)^{2}
$$

\section{Results and discussion}

The equilibrium studies were carried out for three systems, namely TOA, TBP and A336 diluted in MIBK. Being the best extraction system, TOA+ MIBK was chosen for the kinetics studies. Finally, the loading of amine was predicted using the differential evolution algorithm.

\section{Equilibrium distribution of citric acid}

The equilibrium distribution of citric acid is shown in Fig. 1, for both physical (using MIBK 


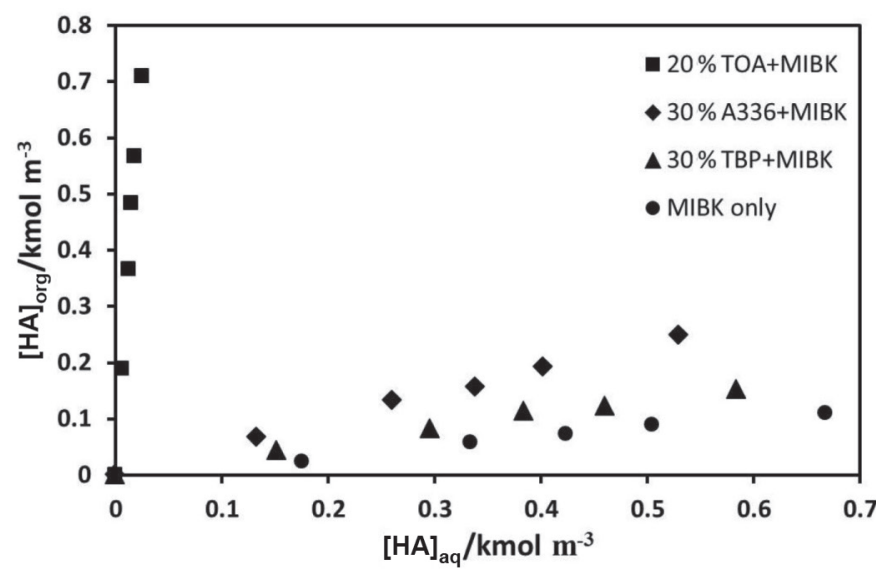

Fig. 1 - Equilibrium distribution isotherms for reactive extraction of citric acid $\left(0.2-0.8 \mathrm{kmol} \mathrm{m}^{-3}\right)$ using different extractants at $T=300 \pm 1 \mathrm{~K}$

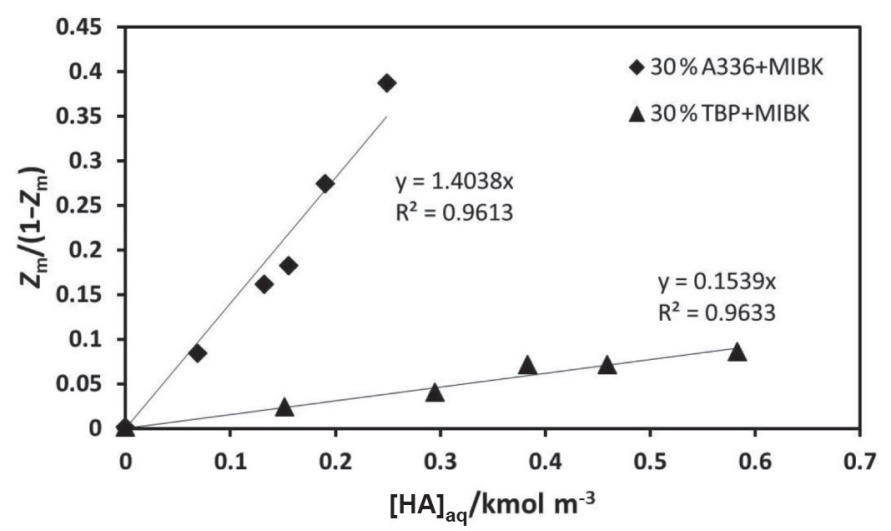

Fig. 2 - Estimation of equilibrium constant for reactive extraction of citric acid using $30 \%(\mathrm{v} / \mathrm{v}) \mathrm{TBP}+\mathrm{MIBK}$ and $30 \%$ (v/v) Aliquat $336+$ MIBK extraction systems

only) and chemical [extractant (TOA/TBP/A336) + MIBK] extraction. Note that the extractants TBP and A336 in a concentration above $30 \%(\mathrm{v} / \mathrm{v})$ significantly extract the acid, while TOA is more efficient, even its $20 \%$ concentration is able to extract more than $90 \%$ of acid from aqueous phase. This is why the concentration of TOA is kept $20 \%(\mathrm{v} / \mathrm{v})$ and the same for TBP and A336 is $30 \%(\mathrm{v} / \mathrm{v})$.

MIBK alone is not able to provide significant extraction $(E \sim 14.93 \%)$. Both the partitioning coefficient $(P)$ and dimerization constant $(D)$ of MIBK were found to be around 0.152 and 0.795 that resulted in a low distribution coefficient $\left(K_{\mathrm{D}}=0.175\right)$. For chemical extraction of citric acid, MIBK as a diluent unusually provides high distribution coefficients, even higher than what would be expected from polarity arguments alone. Thus, extraction efficiency was improved significantly when $30 \%$ $(\mathrm{v} / \mathrm{v})$ TBP $(E=20-22 \%)$ in MIBK was used. The use of extractant $30 \%(\mathrm{v} / \mathrm{v})$ A336 in MIBK could improve extraction up to $34.16 \%$. However, when $20 \%(\mathrm{v} / \mathrm{v})$ concentration of TOA in MIBK was used remarkable extraction efficiency as high as $92.75 \%$ was achieved, while Nikhade et al. ${ }^{10}$ had reported distribution coefficient of $67.147(E=98.5$ \%) using Alamine 336 diluted in MIBK. The extraction efficiency calculated in this work is in good agreement with the literature. ${ }^{10,12}$

The stoichiometry of acid:extractant complex was estimated for chemical extraction of citric acid for all three extraction systems (A336, TBP, and TOA; diluted in MIBK). For TBP and A336, loading ratios $(Z)$ were obtained to be low $(Z<0.5)$, thus, only (1:1) acid:extractant complex formation was assumed. The equilibrium complexation constant $\left(K_{\mathrm{E} 1}\right)$ was estimated by graphical interpretation. Since MIBK is an active diluent (presence of $-\mathrm{C}=\mathrm{O}$ group), its contribution in extraction cannot be neglected. Hence, the net extraction by the extractants can be calculated using the modified loading ratio $\left(Z_{\mathrm{m}}\right)$, which is obtained after subtracting the loading by the diluents alone from the overall loading. The plot of $Z_{\mathrm{m}} /\left(1-Z_{\mathrm{m}}\right)$ vs $[\mathrm{HA}]_{\mathrm{aq}}$ for A336 and TBP is presented in Fig. 2. The equilibrium complexation constant $\left(K_{\mathrm{E}}\right)$ was obtained by regression analysis through linear fitting of equilibrium distribution data. The slope of these loading curves (Eq. 12) directly gives the $K_{\mathrm{E} 1}$ values that were estimated to be $1.405 \mathrm{~m}^{3} \mathrm{kmol}^{-1}$ and $0.154 \mathrm{~m}^{3} \mathrm{kmol}^{-1}$ for $30 \%(\mathrm{v} / \mathrm{v})$ A336+MIBK and $30 \%(\mathrm{v} / \mathrm{v})$ TBP+MIBK, respectively.

In extraction involving TOA, there is a marked effect of the presence of TOA on the extraction of acid (Fig. 1). Higher loading ratios $(Z>0.5)$ were obtained in the studied concentration range of acid and amine, when TOA in MIBK was used as extractant. Kertes and $\mathrm{King}^{8}$ suggested that, for $Z$ values greater than 0.5 (overloading of amine), higher stoichiometry complexes are possible.

Using Fig. 3, equilibrium complexation constant $\left(K_{\mathrm{E} 2}\right)$ for $(2: 1)$ complex was estimated for the extraction of citric acid using TOA in MIBK. According to Eq. 12, from the plot of $Z_{\mathrm{m}} /\left(2-Z_{\mathrm{m}}\right)$ vs $[\mathrm{HA}]_{\mathrm{aq}}{ }^{2}$ the value of $K_{\mathrm{E} 2}$ was obtained as 3715.1 $\left(\mathrm{m}^{3} \mathrm{kmol}^{-1}\right)^{2}$. The higher $K_{\mathrm{E}}$ value obtained using MIBK reveals its capacity to provide better solvation media, and hence, enhanced stability for acid:amine complex.

\section{Kinetics of extraction of citric acid}

Kinetics of extraction of citric acid (0.2-0.8 $\mathrm{kmol} \mathrm{m}^{-3}$ ) have been investigated using extractant TOA diluted in MIBK. The variation of organic phase citric acid concentration with time is shown in Fig. 4. Using $5 \%$ TOA in MIBK, the specific rates of extraction were found to be $0.106,0.087$, and $0.065 \mathrm{kmol} \mathrm{m}^{-3} \mathrm{~min}^{-1}$, when initial concentrations of citric acid were kept at $0.8 \mathrm{kmol} \mathrm{m}^{-3}, 0.6$ 
$\mathrm{kmol} \mathrm{m}^{-3}$, and $0.4 \mathrm{kmol} \mathrm{m}^{-3}$, respectively (Fig. 4). When there was no change in aqueous phase acid concentration, i.e. the time versus concentration curve became horizontal to time axis, the extraction time was optimized accordingly (60 $\mathrm{min})$.

\section{Physical mass transfer coefficient}

For the transfer of citric acid from the aqueous phase to MIBK, the physical mass transfer coefficient $\left(k_{\mathrm{L}}\right)$ was measured to be 0.000549 $\mathrm{kmol}\left(\mathrm{s} \mathrm{m}^{2}\right)^{-1}\left(\mathrm{kmol} \mathrm{m}^{-3}\right)^{-1}$ at a speed of agitation $(N)$ of $1.3 \mathrm{rev} \mathrm{s}^{-1}$ (Fig. 5). Further, to verify the regime of extraction reaction, kinetic experiments were performed. $k_{\mathrm{L}}$ was measured as a function of speed of agitation by contacting the aqueous solution of citric with the diluents, MIBK alone, at different speeds of agitation. Differential mass balance of the batch system for the organic phase can be presented as Eq. 18.

$$
\frac{\mathrm{d}[\overline{\mathrm{HA}}]}{\mathrm{d} t}=k_{\mathrm{L}}\left(\frac{A_{\mathrm{c}}}{V_{\text {org }}}\right)\left(\overline{\mathrm{HA}}^{*}-\overline{\mathrm{HA}}\right)
$$

where, $\overline{\mathrm{HA}}^{*}$ represents the organic phase acid concentration at equilibrium state. A correlation between $k_{\mathrm{L}}$ and $N$ is established as given in Eq. 19.

$$
k_{\mathrm{L}}=0.000567 N^{2}
$$

\section{Reaction regimes}

Experiments were conducted to observe the effects of the volume ratio of the phases and the speed of agitation on the specific rate of extraction using $0.114 \mathrm{kmol} \mathrm{m}^{-3}$ TOA in MIBK at $0.4 \mathrm{kmol} \mathrm{m}^{-3}$ aqueous solution of citric acid.

\section{Effect of agitation speed}

To find the effect of the agitation speed, kinetic experiments were carried out by keeping the initial acid concentration $\left(0.4 \mathrm{kmol} \mathrm{m}^{-3}\right)$ and the volume ratio $(1: 1)$ of the phases constant. In order to have an interfacial area equal to that of the geometric area during extraction, the interface was maintained flat by keeping low speed of stirring (1.30-2.10 $\left.\mathrm{rev} \mathrm{s}^{-1}\right)$. It is known that, at low agitation rates, the surface is not completely renewed during stirring. Thus, under these conditions, the transfer of the acid is controlled by mass transfer resistances. At higher mixing rates, the interface was disturbed and had an interfacial area greater than the geometric area. Fig. 6 shows that the specific rate of extraction does not vary significantly with speed of agitation. For the subsequent experiments, the speed of agitation was kept constant at $1.30 \mathrm{rev} \mathrm{s}^{-1}$.

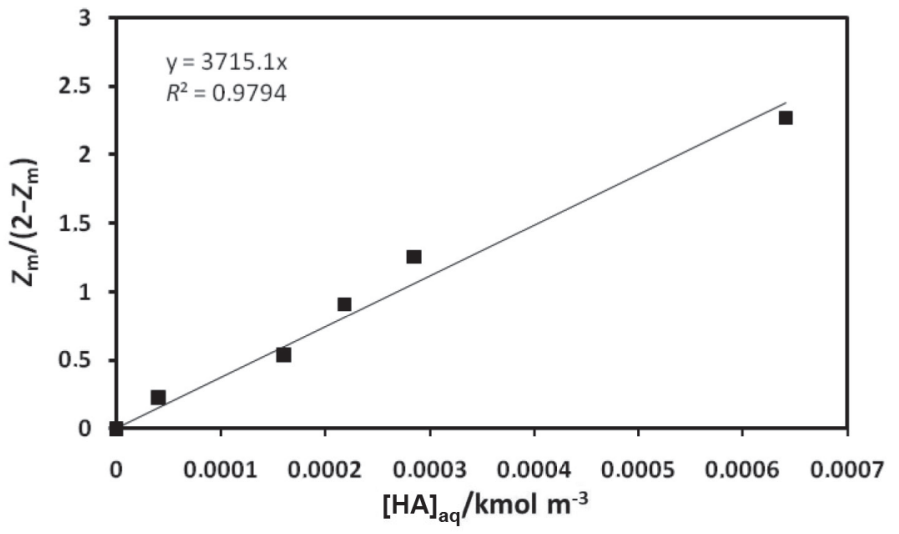

Fig. 3 - Estimation of equilibrium constant for reactive extraction of citric acid using $20 \%(\mathrm{v} / \mathrm{v})$ TOA + MIBK extraction system

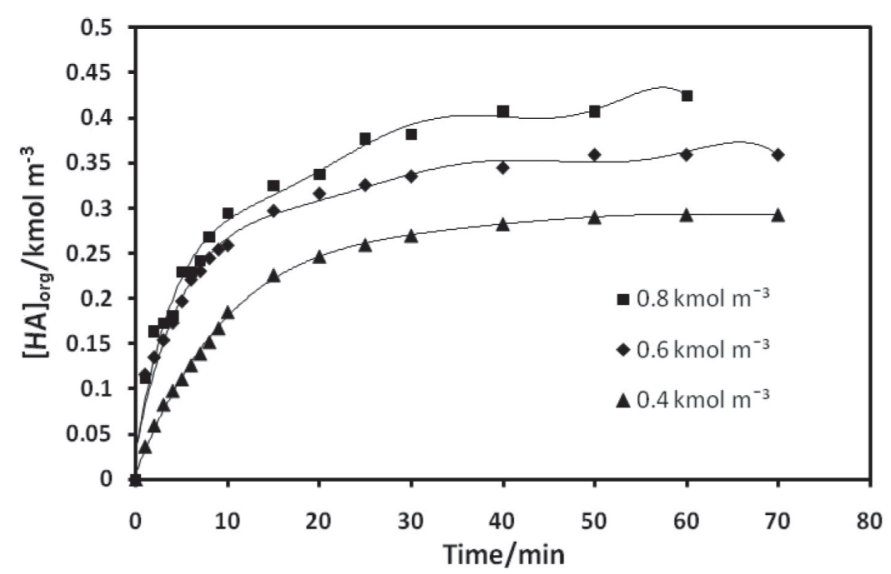

Fig. 4 - Variation of organic phase citric acid concentration with extraction time

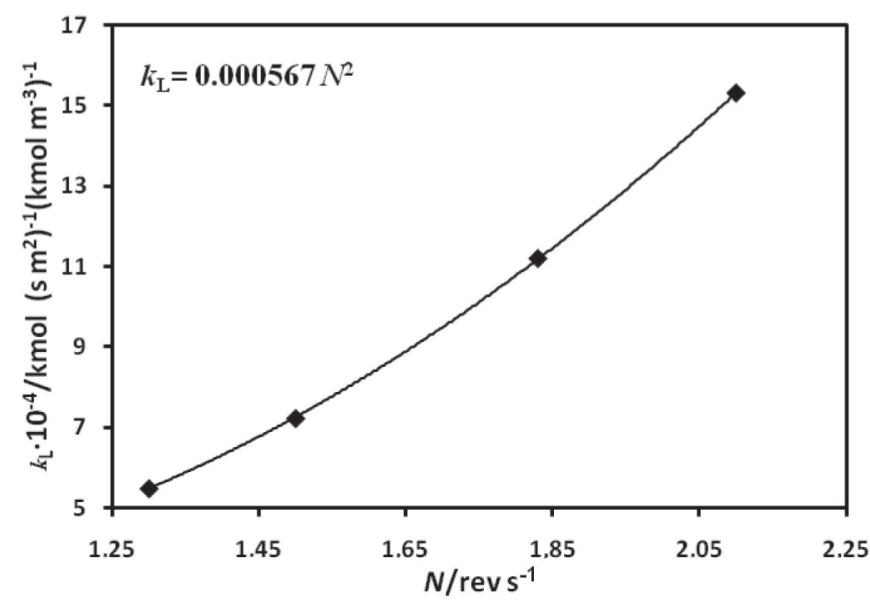

Fig. 5 - Effect of speed of agitation on physical mass transfer coefficient for reactive extraction of citric acid $\left(0.8 \mathrm{kmol} \mathrm{m}^{-3}\right)$ with $5 \%$ TOA in MIBK

\section{Effect of volume phase ratio}

In order to evaluate the effect of the volume ratio of the phases on the specific rate of extraction, experiments were conducted by keeping constant the concentration of the phases $\left(0.8 \mathrm{kmol} \mathrm{m}^{-3}\right)$ and 


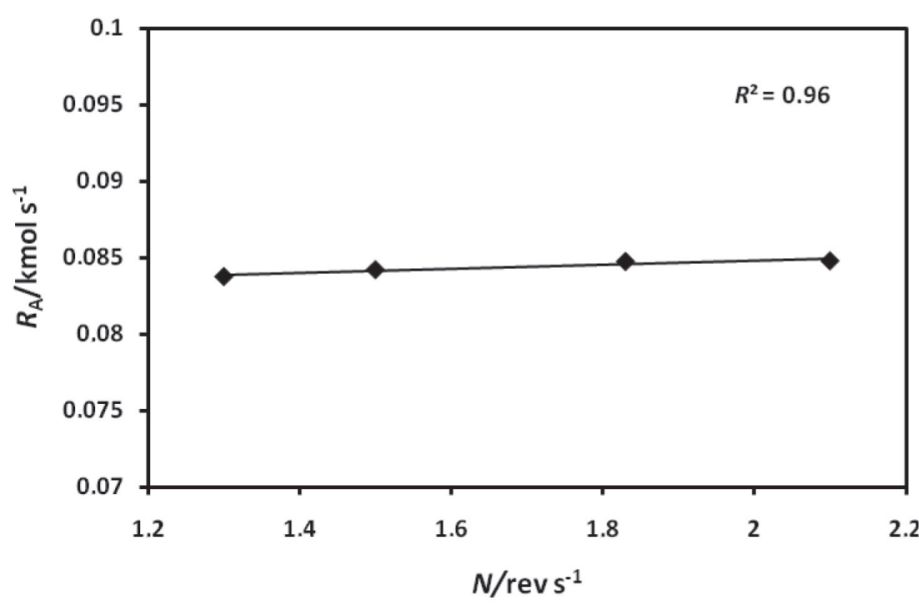

Fig. 6 - Effect of agitation speed on the specific rate of extraction for the reactive extraction of citric acid $\left(0.8 \mathrm{kmol} \mathrm{m}^{-3}\right)$ using $0.114 \mathrm{kmol} \mathrm{m}^{-3}$ TOA in MIBK

the speed of agitation (1.30 $\left.\mathrm{rev} \mathrm{s}^{-1}\right)$, and varying the volume ratio of the organic to aqueous phase from 0.54 to 1 . It can be seen in Fig. 7 that the volume ratio of the phases is directly proportional to the specific rate of extraction for the reactive extraction of citric acid with TOA in MIBK.

Regime of extraction accompanied by chemical reaction

Results of preliminary studies conducted in order to discern the regime of extraction reaction of citric acid using TOA in MIBK confirm that the specific rate of extraction, $R_{\mathrm{A}}$, is directly proportional to initial acid concentration and volume phase ratio $\left(V_{\text {org }} / V_{\text {aq }}\right)$ (Fig. 7); and is unaffected by the speed of agitation, $N$ (Fig. 6). Thus, with reference to discerning the mechanism, it can be concluded that the extraction reaction between citric acid and TOA in MIBK falls into Regime 1 that is a very slow reaction. The governing equation for the rate of chemical reaction in this regime is as given in Eq. $20:^{17}$

$$
R_{\mathrm{A}}=l k_{m n}\left[\mathrm{H}_{3} \mathrm{~A}\right]^{m}\left[E^{\mathrm{o}}\right]^{n}
$$

where, $m$ and $n$ are the orders of the reaction with respect to acid and extarctant, respectively. $k_{m n}$ is the rate constant for a $m^{\text {th }}$ and $n^{\text {th }}$ order reaction. The proportionality constant $l$ represents the liquid holdup.

\section{Order of the extraction reaction}

The effect of the reactants concentration on the specific rate of extraction was investigated by keeping the concentration of one of the reactants constant, and varying the other at a fixed speed of agitation $\left(1.30 \mathrm{rev} \mathrm{s}^{-1}\right)$ and the volume ratio of phases (1:1). The initial concentration of TOA was varied

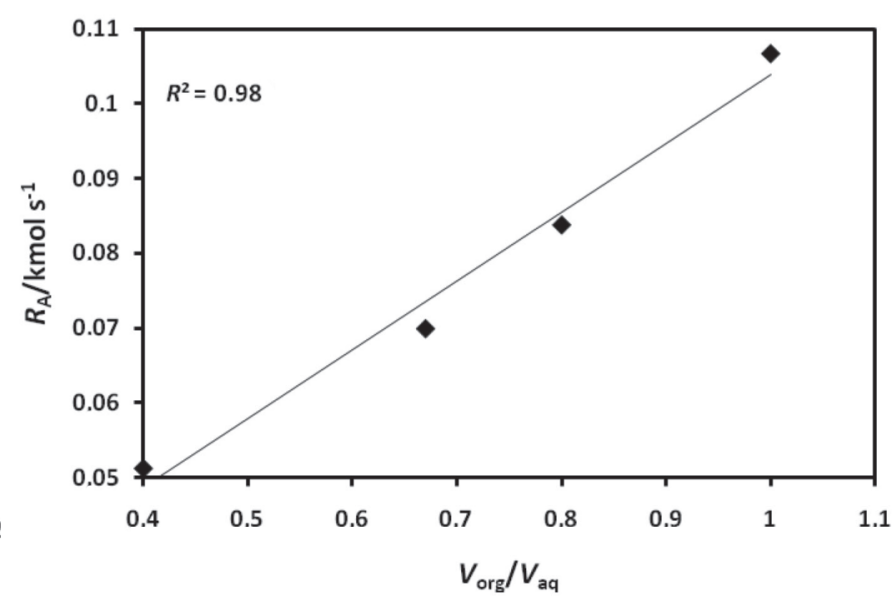

Fig. 7 - Effect of volume ratio of the phases on the specific rate of extraction for the reactive extraction of citric acid $(0.8$ $\mathrm{kmol} \mathrm{m}^{-3}$ ) using $0.114 \mathrm{kmol} \mathrm{m}^{-3}$ TOA in MIBK

between $0.114 \mathrm{kmol} \mathrm{m}^{-3}$ to $0.457 \mathrm{kmol} \mathrm{m}^{-3}$, while that of equilibrium concentration of citric acid was varied from $0.2-0.8 \mathrm{kmol} \mathrm{m}^{-3}$.

Fig. 8 and Fig. 9 depict the variation of specific rate of extraction, $R_{\mathrm{A}}$ with the initial extractant (TOA) concentration $\left(\left[E^{\circ}\right]\right)$ in the organic phase and initial concentration of citric acid $\left(\left[\mathrm{H}_{3} \mathrm{~A}\right]_{\mathrm{aq}}\right)$ in the aqueous phase, respectively. Using the method of least squares, based on a linear approximation, the reaction was found to be first order with respect to both the reactants, citric acid and TOA. Replacing the values of $m$ and $n(m=n=1)$, Eq. 20 simplifies to Eq. 21

$$
R_{\mathrm{A}}=l k_{2}\left[\mathrm{H}_{3} \mathrm{~A}\right]\left[E^{\mathrm{o}}\right]
$$

Specific reaction rate constant

Using Eq. 21, from the slope of Fig. 10, second order rate constant, $k_{2}$, was estimated to be 0.0351 $\mathrm{m}^{3} \mathrm{kmol}^{-1} \mathrm{~s}^{-1}$, which is in close agreement with the value reported by Nikhade et al. ${ }^{10}\left(0.013 \mathrm{~m}^{3} \mathrm{kmol}^{-1} \mathrm{~s}^{-1}\right)$ for citric acid extraction using Alamine 336 diluted in MIBK. According to Doraiswamy and Sharma, ${ }^{20}$ for the validity of Regime 1, condition as given by Eq. 16 must be satisfied. For the present case, the extraction reaction falls into the regime that corresponds to a very slow reaction occurring in the bulk with no reaction at the diffusion film. ${ }^{20}$

\section{Process optimization using differential evolution}

The model equation (Eq. 6) correlating distribution coefficient $\left(K_{\mathrm{D}}\right)$ to the equilibrium constant $\left(K_{\mathrm{E}}\right)$ and stoichiometry of the acid:extractant complex $(m, n)$ was solved using differential evolution optimization technique. The optimized values of $m$, $n$, and the equilibrium complexation constants $\left(K_{\mathrm{E}}\right)$ are presented in Table 2. Model equation (Eq. 6) 


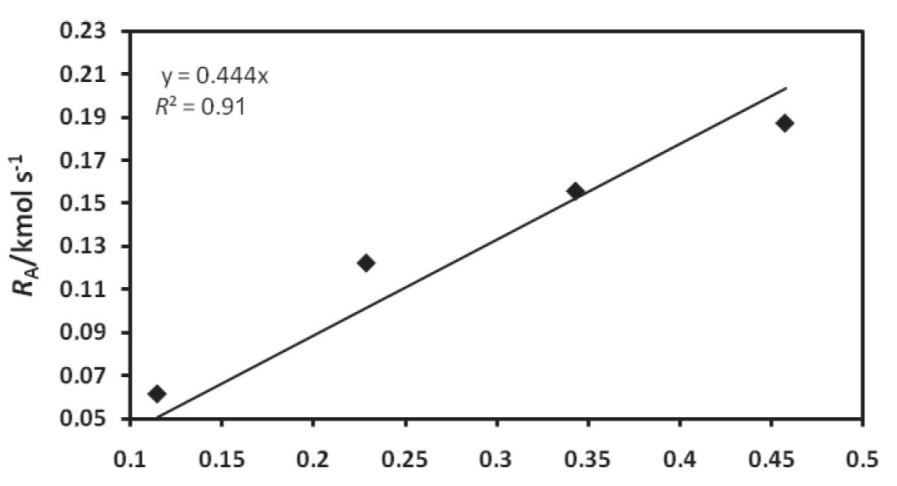

$\left[E^{\circ}\right] / \mathrm{kmol} \mathrm{m}^{-3}$

Fig. 8 - Effect of TOA concentration (0.114 to $\left.0.457 \mathrm{kmol} \mathrm{m}^{-3}\right)$ on the specific rate of extraction for reactive extraction of citric acid $\left(0.4 \mathrm{kmol} \mathrm{m}^{-3}\right)$

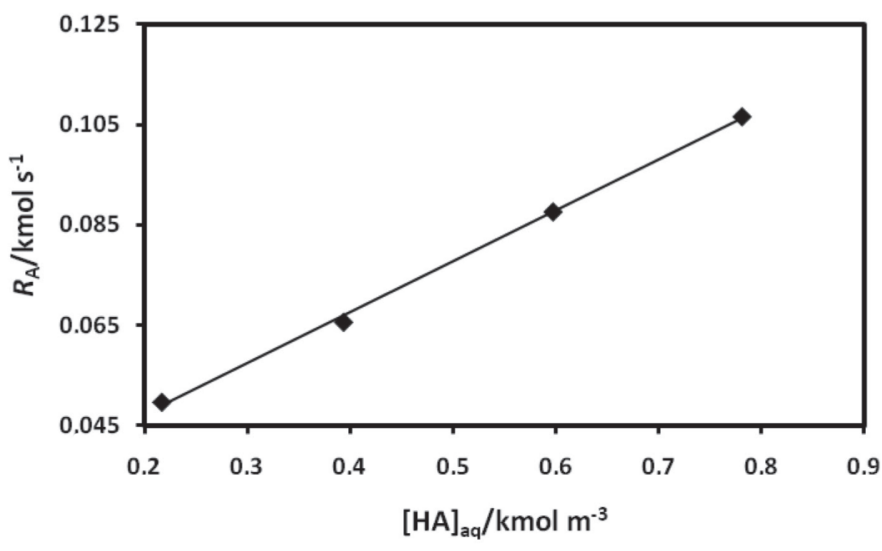

Fig. 9 - Effect of initial acid concentration on specific rate of extraction for reactive extraction of citric acid with TOA $\left(0.114 \mathrm{kmol} \mathrm{m}^{-3}\right)$ diluted in MIBK

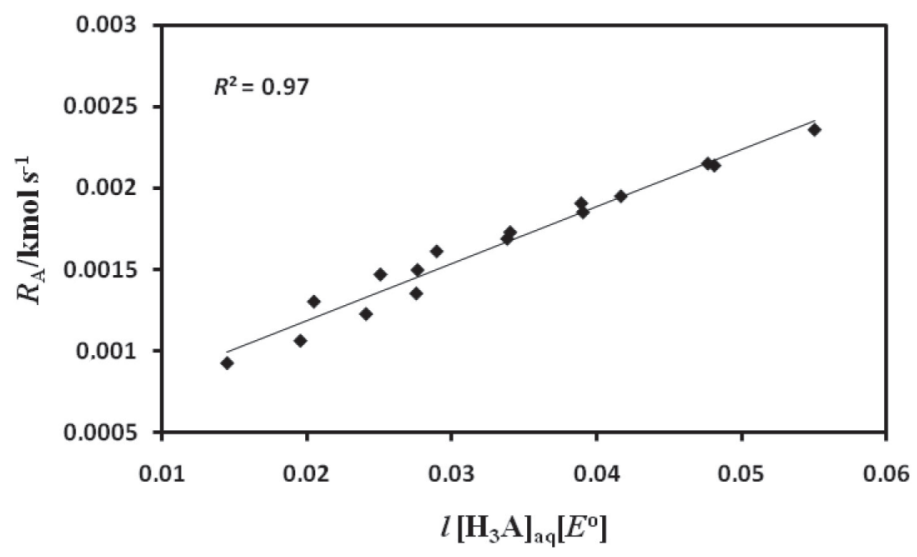

Fig. 10 - Estimation of the second order rate constant for the reaction between citric acid and TOA in MIBK

was used for the calculation of corresponding model values of $K_{\mathrm{D}}$, based on the optimized values. The predicted values of $K_{\mathrm{D}}$ for each extraction system using DE approach shows a good resemblance with the experimental values of $K_{\mathrm{D}}$. In the extraction of citric acid using TBP, TOA, and A336, the predicted
Table 2 -Optimum values of $K_{E}, m$ and $n$ estimated using differential evolution for reactive extraction of citric acid using different extractants (TOA/TBP/A336) in MIBK

\begin{tabular}{l|c|c|c|c}
\hline Extraction system & $\begin{array}{c}K_{\mathrm{E}} \\
\left(\mathrm{m}^{3} \mathrm{kmol}^{-1}\right)^{2}\end{array}$ & $m$ & $n$ & $\mathrm{SE}^{\mathrm{a})}$ \\
\hline $20 \%$ TOA+MIBK & 3627.2 & 2.0000 & 1 & 1.0000 \\
$30 \% \mathrm{~A} 336+\mathrm{MIBK}$ & 1.0134 & 1.1635 & 1 & 0.0001 \\
$30 \% \mathrm{TBP}+\mathrm{MIBK}$ & 0.3062 & 0.9555 & 1 & 0.0000 \\
\hline
\end{tabular}

a) SE: Standard Error

values of $K_{\mathrm{D}}$ show a slight deviation from experimental values of $K_{\mathrm{D}}$ at lower acid concentrations. This may be due to the precision in the measurement of the very low concentration during experimental analysis when very low initial acid concentration was used. Applying the above strategy, a computer program using MATLAB ${ }^{\circledR} 7.1$ was generated and the optimized values were obtained.

At higher concentrations of TOA, the extraction of citric acid was very high. Consequently, the concentration of aqueous phase acid left was very low. Thus, error in measurement of low acid concentration resulted in a significant deviation between model values and experimental values of $K_{\mathrm{D}}$ particularly in the case of TOA as compared to TBP and A336. In the case of extraction of citric acid using TOA, the higher strength of the complex solvation was found for all the diluents as the $K_{\mathrm{E}}$ values were found to be extremely high (Table 2). A higher affinity of tertiary amine group towards carboxylic acid favors the stable acid:amine complex and a high forward reaction rate result in a higher $K_{\mathrm{E}}$ values $\left(3627.2\left(\mathrm{~m}^{3} \mathrm{kmol}^{-1}\right)^{2}\right)$ for TOA. ${ }^{8}$ This also promoted the higher extractant loading emphasizing the formation of (2:1) acid-amine complex. The FTIR spectroscopic evidence for the overloading of amine is given in our previous work. ${ }^{14}$ Note that the same phenomenon was also observed for quaternary amine, i.e., A336, for which the loading ratio was greater than unity $(m=1.1635)$. However, A336 was not much efficient compared to TOA due to the steric hindrance. Whereas, the overloading in the case of phosphate bearing extractants was totally absent which was reflected from the loading value for TBP, i.e. $m=0.9555$, that was less than unity. The formation of acid:amine complexes also depended on the nature of diluents, which affect the basicity of the amine and the stability of the ion pair formed in the extract phase. The synergistic extraction strength of the TOA+MIBK system was remarkably high due to the simultaneous effect of the physical extraction in addition to chemical interaction through hydrogen bonding. ${ }^{21-23}$ MIBK affected the diluent complex aggregation more readily through hydrogen bonding and dipole-dipole inter- 
action than the amine-free diluent-acid association. These results envisage that the diluents are involved not only in the physical extraction, but also enhance the polarity of extractant.

\section{Conclusions}

Extraction equilibria of citric acid using three different extractants, TBP, TOA and A336 in MIBK have been studied. Among all extraction systems, TOA in MIBK has been observed to be the most efficient, enabling $\sim 92 \%\left(K_{\mathrm{D}, \text { avg }}=11.74\right)$ extraction of citric acid from aqueous solutions. Kinetic studies provided that the citric acid-TOA complexation reaction fall under the very slow reaction regime with overall second order rate constant of 0.0351 $\mathrm{m}^{3} \mathrm{kmol}^{-1} \mathrm{~s}^{-1}$. Only (1:1) stoichiometry of acidextractant complex was observed with both A336 and TBP in MIBK with $K_{\mathrm{E} 1}=1.405 \mathrm{~m}^{3} \mathrm{kmol}^{-1}$ and $0.154 \mathrm{~m}^{3} \mathrm{kmol}^{-1}$ respectively, while $(2: 1)$ complex was observed with TOA in MIBK with $K_{\mathrm{E} 2}=3715.1$ $\left(\mathrm{m}^{3} \mathrm{kmol}^{-1}\right)^{2}$. The analogous results are found with the mathematical model, optimized by differential evolution technique. The findings of the present study are useful in the design and development of extraction equipment.

\section{ACKNOWLEDGEMENT}

I (Dharm Pal) would like to extend my sincere thanks to the CCOST, Raipur, India for the financial support provided through sponsored project (Endt. No. 435/CCOST/MRP/2014).

\section{Nomenclature}

$A_{\mathrm{C}} \quad-$ Cross-sectional area of stirred tank, $\mathrm{m}^{2}$

$K_{\mathrm{a}} \quad-$ Citric acid dissociation constant, $\left(\mathrm{kmol} \mathrm{m}^{-3}\right)^{3}$

$K_{\text {D }} \quad-$ Distribution coefficient, -

$K_{\mathrm{E}}-$ Overall equilibrium complexation constant, -

$K_{\mathrm{E} 1} \quad-(1: 1)$ acid-extractant equilibrium complexation constant, $\mathrm{m}^{3} \mathrm{kmol}^{-1}$

$K_{\mathrm{E} 2}-(2: 1)$ acid-extractant equilibrium complexation constant, $\left(\mathrm{m}^{3} \mathrm{kmol}^{-1}\right)^{2}$

$k_{m n} \quad-$ Reaction rate constant: $(m+n)^{\text {th }}$ order, $\left(\mathrm{m}^{3} \mathrm{kmol}^{-1}\right)^{\mathrm{m}+\mathrm{R}-1} \mathrm{~s}^{-1}$

$l \quad$ - Liquid holdup, -

$m \quad-$ Number of acid molecules in complex, -

$n \quad-$ Number of extractant molecules in complex, -

$R_{\mathrm{A}} \quad-$ Reaction rate, $\mathrm{kmol} \mathrm{m}^{-3} \mathrm{~s}^{-1}$

$V_{\text {aq }} \quad$ - Aqueous phase volume, $\mathrm{m}^{3}$

$V_{\text {org }} \quad$ - Organic phase volume, $\mathrm{m}^{3}$

$Z$ - Loading ratio, -
$Z_{\mathrm{m}} \quad-$ Modified loading ratio, -
$\mu \quad-$ Acid taken by diluent alone per unit extract- ant concentration, -
$v \quad-$ Diluent's fraction in organic phase, -

\section{References}

1. Wang, B., Chen, J., Li, H., Sun, F., Li, Y., Shi, G., Efficient production of citric acid in segmented fermentation using Aspergillus niger based on recycling of a pellet-dispersion strategy, RSC Adv. 6 (2016) 105003. doi: https://doi.org/10.1039/C6RA13648F

2. Weikle K., Determination of citric acid in fruit juices using HPLC, Con. Coll. J. Anal. Chem. 3 (2012) 57.

3. Sass-Kiss, A., Toth-Markus, M., Sass, M., Chemical composition of citrus fruits (orange, lemon, and grapefruit) with respect to quality control of juice products, ACS Symp. Ser. 871 (2004) 24. doi: https://doi.org/10.1021/bk-2004-0871.ch003

4. Barrington, S., Kim, J. S., Wang, L., Kim, J. W., Optimization of citric acid production by Aspergillus niger NRRL 567 grown in a column bioreactor, Korean J. Chem. Eng. 26 (2009) 422. doi: https://doi.org/10.1007/s11814-009-0071-4

5. Pal, D., Keshav, A., Extraction equilibria of pyruvic acid using tri- $n$-butyl phosphate: Influence of diluents, J. Chem. Eng. Data. 59 (2014) 2709. doi: https://doi.org/10.1021/je500125j

6. Pal, D., Tripathi, A., Shukla, A., Gupta, K. R., Keshav, A., Reactive extraction of pyruvic acid using tri- $n$-octylamine diluted in decanol/kerosene: equilibrium and effect of temperature, J. Chem. Eng. Data. 60 (2015) 860. doi: https://doi.org/10.1021/je500964e

7. Marsh, K. N., Deev, A., Wu, A. C., Tran, E. Klamt, A., Room temperature ionic liquids as replacements for conventional solvents-a review, Korean J. Chem. Eng. 19 (2002) 357. doi: https://doi.org/10.1007/BF02697140

8. Kertes, A. S., King C. J., Extraction chemistry of fermentation product carboxylic acids, Biotechnol. Bioeng. 28 (1986) 269. doi: https://doi.org/10.1002/bit.260280217

9. Bízek, V., Horáček, J., Koušová, M., Amine extraction of citric acid: effect of diluent, Chem. Eng. Sci. 48 (1993) 1447. doi: https://doi.org/10.1016/0009-2509(93)80051-Q

10. Nikhade, B. P., Moulijn, J. A., Pangarkar, V. G., Extraction of citric acid from aqueous solutions with Alamine 336 : equilibrium and kinetics, J. Chem. Technol. Biotechnol. 79 (2004) 1155.

doi: https://doi.org/10.1002/jctb.1109 
11. Han, D. H., Hong, Y. K., Hong, W. H., Separation characteristics of lactic acid in reactive extraction and stripping, Korean J. Chem. Eng. 17 (2000) 528. doi: https://doi.org/10.1007/BF02707161

12. Poposka, F. A., Nikolovski, K., Tomovska, R., Kinetics, mechanism and mathematical modelling of extraction of citric acid with isodecanol/n-paraffins solutions of trioctylamine, Chem. Eng. Sci. 53 (1998) 3227. doi: https://doi.org/10.1016/S0009-2509(98)00125-0

13. Pal, D., Keshav, A., Kinetics of reactive extraction of pyruvic acid using tributylamine dissolved in $n$-butyl acetate, Int. J. Chem. React. Eng. 13 (2015) 63. doi: https://doi.org/10.1515/ijcre-2014-0117

14. Thakre, N., Prajapati, A. K., Mahapatra, S. P., Kumar, A., Khapre, A., Pal, D., Modeling and optimization of reactive extraction of citric acid, J. Chem. Eng. Data 61 (2016) 2614. doi: https://doi.org/10.1021/acs.jced.6b00274

15. Wasewar, K. L., Heesink, A. B. M., Versteeg, G. F., Pangarkar, $V$. G., Reactive extraction of lactic acid using alamine 336 in MIBK: equilibria and kinetics, J. Biotechnol. 97 (2002) 59. doi: https://doi.org/10.1016/S0168-1656(02)00057-3

16. Kumar, S., Datta, D., Babu, B. V., Experimental data and theoretical (chemodel using the differential evolution approach and linear solvation energy relationship model) predictions on reactive extraction of monocarboxylic acids using tri- $n$-octylamine, J. Chem. Eng. Data 55 (2010) 4290. doi: https://doi.org/10.1021/je100449c

17. Wasewar, K. L., Heesink, A. B. M., Versteeg, G. F., Pangarkar, $V$. G., Reactive extraction of lactic acid using ala- mine 336 in MIBK: equilibria and kinetics, J. Biotechnol. 97 (2002) 59. doi: https://doi.org/10.1016/S0168-1656(02)00057-3

18. Geanta, R. M., Ruiz, M. O., Escudero, I., Micellar-enhanced ultrafiltration for the recovery of lactic acid and citric acid from beet molasses with sodium dodecyl sulphate, J. Membr. Sci. 430 (2013) 11. doi: https://doi.org/10.1016/j.memsci.2012.12.006

19. Gaidhani, H. K., Wasewar, K. L., Pangarkar, V. G., Intensification of enzymatic hydrolysis of penicillin G: Part 1. Equilibria and kinetics of extraction of phenyl acetic acid by Alamine 336, Chem. Eng. Sci. 57 (2002) 1979 doi: https://doi.org/10.1016/S0009-2509(02)00078-7

20. Doraiswamy, L. K., Sharma, M. M., Heterogeneous Reactions: Analysis, Examples, and Reactor Design: 1st ed., Vol. 2, John Wiley \& Sons, New York, 1984, pp 17-41.

21. Pal, D., Thakre, N., Kumar, A., Keshav, A., Reactive extraction of pyruvic acid using mixed extractants, Sep. Sci. Technol. 51 (2016) 1141. doi: https://doi.org/10.1080/01496395.2016.1143508

22. Datta, D., Marti, M. E., Pal, D., Kumar, S., Equilibrium Study on the extraction of levulinic acid from aqueous solution with Aliquat 336 dissolved in different diluents: Solvent's polarity effect and column design, J. Chem. Eng. Data 62 (2016) 3. doi: https://doi.org/10.1021/acs.jced.6b00164

23. Uslu, H., Bamufleh, H. S., Keshav, A., Pal, D., Demir, G., Extractive separation of pentanedioic acid by Amberlite LA-2 in various solvents, J. Chem. Eng. Data 61 (2016) 2450 . doi: https://doi.org/10.1021/acs.jced.6b00141 